\title{
0 significado de competência para o docente de administração em enfermagem*
}

\author{
THE MEANING OF COMPETENCE FOR NURSING MANAGEMENT FACULTY MEMBERS \\ EL SIGNIFICADO DE COMPETENCIA PARA EL DOCENTE DE ADMINISTRACIÓN EN ENFERMERÍA
}

\author{
Miriam Aparecida Nimtz'ㄹ, Maria Helena Trench Ciampone ${ }^{2}$
}

\section{RESUMO}

Este estudo tem como objetivos: identificar as percepções dos professores que atuam em disciplinas de Administração em Enfermagem, quanto ao significado de competência docente, nesse âmbito do ensino de Graduação; analisar e problematizar os significados atribuídos à competência docente, visando propor intervenções que favoreçam propostas de capacitação para o ensino do gerenciamento, compatíveis com a Política de Ensino e com as atuais Diretrizes Curriculares. Para tanto, foi utilizado o método da análise de conteúdo em doze discursos de professores de Administração em Enfermagem, em exercício nas Instituições Particulares de Ensino da Grande São Paulo, no período de agosto a outubro de 2002. $\mathrm{O}$ significado e as percepções relatados foram categorizados e, diante do revelado, recomendamos uma política de desenvolvimento de recursos humanos que privilegie o processo de capacitação docente, oferecendo oportunidades concretas para que o desenvolvimento docente impulsione transformações rumo a uma educação emancipatória.

\section{ABSTRACT}

This study is aimed at identifying and analyzing the perceptions of professors who work on Nursing Management disciplines regarding the meaning of faculty competence at the undergraduate level. The objective is to suggest interventions that favor proposals for capacity building for the teaching of management that are compatible with teaching norms and with the current Curriculum Guidelines. In order to do so, the content analysis method was applied in twelve discourses of Nursing Management professors who teach in private institutions in the Greater São Paulo area between August and October of 2002. The meaning and perceptions reported were categorized, and the authors recommend a policy of human resources development that offers concrete opportunities that faculty development will lead to changes toward an emancipating education.

\section{KEY WORDS}

Competency-based education.

Education, nursing.

Professional competence.

\section{RESUMEN}

En este estudio se tuvo como objetivos: identificar las percepciones de los profesores que trabajan en disciplinas de Administración en Enfermería, en cuanto al significado de la competencia docente, en el ámbito de la enseñanza del Pregrado; analizar y problematizar los significados atribuidos a la competencia docente, con el objetivo de proponer intervenciones que favorezcan propuestas de capacitación en la enseñanza de la gerencia, compatibles con la Política de Enseñanza y con las actuales Directivas Curriculares. Para tal efecto, fue utilizado el método del análisis de contenido en doce discursos de profesores de Administración en Enfermería, en ejercicio, en las Instituciones Particulares de Enseñanza de la Gran San Pablo, en el período de agosto a octubre del 2002. El significado y las percepciones relatadas fueron categorizadas y, frente a lo revelado, recomendamos una política de desarrollo de recursos humanos que privilegie el proceso de capacitación docente, ofreciendo oportunidades concretas para que el desarrollo docente impulse transformaciones rumbo a una educación emancipadora.

\section{DESCRIPTORES}

Educación basada en competencias.

Educación en enfermería.

Competencia profesional. competências.

Educação em enfermagem.

Competência profissional.

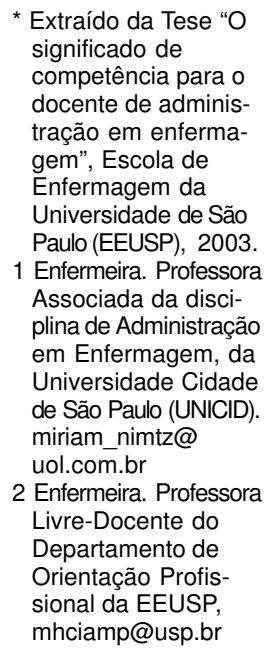




\section{INTRODUÇÃO}

Em 1999 desenvolvemos um estudo onde descrevemos e analisamos os programas de ensino das disciplinas de Administração em Enfermagem, visando conhecer o perfil de formação, nessa área específica, dos enfermeiros formados nas escolas de graduação da Grande São Paulo. Os resultados apontaram para a necessidade de um repensar a formação dos futuros enfermeiros, a fim de impulsionar mudanças na assistência, no gerenciamento, nas relações de trabalho e, também, no modo de organização dos diferentes processos de trabalho. Percebemos assim, a importância de prosseguir a investigação. A continuidade do processo investigativo dirigiu nossa atenção para a necessidade de pensar, criticamente, a competência docente para o desenvolvimento do processo educativo. Portanto, o presente trabalho justifica-se pelo fato de reconhecermos que, como professores da disciplina de Administração em Enfermagem, somos educadores e temos o desafio de formar futuros enfermeiros, os quais deverão estar capacitados para desenvolver os processos de trabalho assistencial, gerencial e educativo.

Na era da pós-modernidade, marcada pelos avanços tecnológicos e pela crescente informatização, a educação e a escola acumulam, neste século, problemas não resolvidos em função das rápidas transformações do mundo, da sociedade e do conhecimento. Tais transformações têm reflexos no âmbito econômico, político, social e cultural. O educador, de modo geral, tem atuado em um contexto que apresenta como cenário, as crônicas crises brasileiras, as quais acumulam soluções insatisfatórias aos problemas da educação, sendo, também, depositário de múltiplas dificuldades e sofrendo desvalorizações dentro e fora da escola. Sabe-se que as crises agudizam dificuldades crônicas, mas, também, podem ser oportunidades para rever valores e paradigmas.

Redescobrir o papel profissional do educador e incorporar novos enfoques ao seu desempenho são desafios assumidos por aqueles que se preocupam com a qualidade da educação.

A educação é algo abrangente, complexo, contínuo e criativo; por isso, para atuar nesse cenário é preciso ter, além de conhecimentos atualizados e contextualizados, um olhar constantemente dirigido para as práticas historicamente constituídas. Assim, através da consciência crítica, é possível revisitar e questionar os modelos e as práticas educacionais, para que seja possível analisar as influências exercidas por esses na prática educativa.

No que se refere ao ensino e à atuação do professor de enfermagem no contexto nacional, pesquisadores ${ }^{(1)}$ pontuam que:
Quando se fala nas crises que o Brasil vem enfrentando, o setor educação parece estar ocupando lugar de destaque, pela gravidade e constância de seus problemas. Tal crise tem suas características inerentes ao setor educacional, mas não deixa de sofrer os reflexos dos problemas enfrentados por vários outros setores, cujos resultados finais, com relação ao ensino, têm também repercussões na sociedade como um todo. A qualidade do ensino em geral, assim como no ensino da enfermagem, vem sendo muito criticada nos últimos tempos. São vários os aspectos que devem ser repensados no que se refere aos conteúdos, às práticas de ensino e outras atividades desenvolvidas.

É necessário que o docente de enfermagem se conscientize dos determinantes sociais que interferem no ensino e, dentro dos limites estabelecidos por essa compreensão, aceite o desafio de inovar sua atuação, inovação esta que só é possível a partir do desenvolvimento de sua própria competência, enquanto professor. Nessa ótica, a Lei de Diretrizes e Bases da Educação Nacional, no que tange às novas Diretrizes Curriculares Nacionais do Curso de Graduação em Enfermagem, apontam para a necessidade de mudanças que permitam transformar o perfil profissional, rompendo com equívocos até então presentes nas propostas curriculares anteriores, tais como: a fragmentação do eixo de formação e o desenvolvimento de conteúdos estanques. Tais dispositivos legais que regem o ensino da enfermagem não são específicos para a formação do professor e para a atividade docente, porém as propostas apresentadas para a formação atual do enfermeiro, como por exemplo, o perfil do profissional a ser formado (generalista, crítico, reflexivo e capaz de intervir sobre os problemas/situações de saúde/doença mais prevalentes na região de sua atuação), deixam claro que este perfil deve ser construído a partir de competências e habilidades, tendo a pesquisa como eixo integrador da formação acadêmica. É indispensável que os docentes de enfermagem repensem a prática educacional e reflitam sobre sua capacitação, bem como sobre sua própria competência para tal.

Considerando que os professores são mediadores do processo ensino-aprendizagem e, ao que tudo indica, não estão suficientemente preparados para empreender a nova proposta de formação que se ancora no desenvolvimento do pensamento crítico, pois não vivenciaram uma formação crítica, esta situação configura-se a um problema.

O ensino de Administração em Enfermagem, no que diz respeito à nova proposta do Ministério da Educação, deverá propiciar ao educando o desenvolvimento de competências e habilidades, a fim de este - quando for profissional esteja apto para o exercício do processo de trabalho de 
gerenciamento, que tem como meios e instrumentos a força de trabalho, os recursos físicos e materiais e o saber administrativo. De modo geral, espera-se que os enfermeiros estejam aptos a ser gestores e líderes na equipe de saúde.

Sendo assim, os fundamentos de tal disciplina deverão contemplar aspectos sociais, econômicos, políticos e aspectos do desenvolvimento científico e tecnológico na área gerencial. Portanto, a importância de repensar o ensino de Administração em Enfermagem e as competências de referência para a prática docente constitui-se em um desafio, tornando-se, cada vez mais, uma decisão consciente.

Em um estudo feito com o propósito de desvelar as percepções dos docentes universitários em relação à própria capacitação para o ensino em Enfermagem, as docentes ${ }^{(2)}$ da disciplina de Administração Aplicada à Enfermagem, têm manifestado suas inquietações sobre as múltiplas variáveis do processo educativo que afetam tanto o professor quanto o aluno, como: interesses, atitudes, formas de pensar e agir, valores e experiências anteriores, sendo levadas a repensar a forma de vivenciar a prática educacional e a refletir sobre a capacitação docente. As autoras concluem, após a análise dos discursos de docentes da referida disciplina, que:

O professor, considerado como elemento mediador do processo ensino-aprendizagem, tem influência direta nas situações que ocorrem em sala de aula, no relacionamento aluno/professor, no planejamento e adequação das condições de aprendizagem e no relacionamento com os demais docentes. Nessa perspectiva, percebemos a necessidade da capacitação profissional contínua do docente para o ensino em todas essas dimensões. A capacitação do professor é resultante de um processo complexo e contínuo de preparo técnico, teórico e pedagógico, sendo que deve ser estudado dentro dos múltiplos cenários técnico, econômico, político, social, ético, histórico e psicológico(2).

Enfim, para analisar o processo ensino-aprendizagem, em qualquer área, deve-se contextualizá-lo no momento histórico, político, econômico e social do grupo e do cenário enfocado. É um processo dinâmico que exige do docente constante reflexão, revisão de sua atuação, de conhecimentos, de valores, de interesses e atitudes, tudo em relação ao ensino, mas - sobretudo - avaliação da própria postura.

Para iluminar tal idéia, existem autores que pontuam que o docente enfermeiro tem, diante de si, grande responsabilidade, pois ao formar o profissional que será líder e gestor, avança para além da capacitação requerida aos enfermeiros assistenciais $^{(3)}$. Consiste em preparar responsáveis pela evolução dos quadros da própria enfermagem, enquanto profissão.

Assim sendo, explicitamos algumas das questões norteadoras que formam nossos pontos de partida para a edificação dos pontos fundamentais desta investigação:
- Qual o significado que os docentes atribuem à sua atuação como professores de Administração em Enfermagem?

- O que vem a ser competência docente para os professores da disciplina de Administração em Enfermagem?

- Como estes docentes direcionam a aquisição de competências para o exercício do trabalho docente?

As respostas a estas questões vão ao encontro dos objetivos desse estudo, relacionados a seguir.

\section{OBJETIVOS}

- Identificar as percepções dos professores que atuam em disciplinas de Administração em Enfermagem, quanto ao significado de competência docente, no âmbito do ensino de Graduação.

- Analisar e problematizar os significados atribuídos à competência docente, visando propor intervenções que favoreçam propostas de capacitação docente para o ensino do gerenciamento, compatíveis com a Política de Ensino e com as atuais Diretrizes Curriculares.

\section{METODOLOGIA}

Para a realização desse estudo compreensivo-descritivo, optamos pela abordagem qualitativa de pesquisa $^{(4)}$, na vertente da técnica da análise de conteúdo, permitindo, assim, que se vá ao encontro das experiências e vivências dos docentes da disciplina de Administração em Enfermagem, propiciando - a partir de seus discursos - a concepção sobre os questionamentos propostos e a reflexão crítica do cotidiano profissional. O projeto de pesquisa foi submetido e aprovado pelo Comitê de Ética em Pesquisa da EEUSP.

A princípio, foram selecionadas doze Instituições Particulares de Ensino de Graduação em Enfermagem, no âmbito da Grande São Paulo. Foi enviada uma carta às Instituições, esclarecendo os objetivos da pesquisa; solicitando aos Diretores do curso de Graduação em Enfermagem a permissão para realizar a entrevista com um dos docentes da referida disciplina. A participação dos docentes foi voluntária, tendo-se obtido o consentimento livre e esclarecido de cada um, no momento da entrevista.

O nome dos docentes, bem como o das Instituições de Ensino envolvidos neste estudo foram mantidos em sigilo, conforme os padrões éticos da pesquisa. Foram utilizados nomes de flores, com a intenção de denominar os docentes e suas respostas.

Sendo assim, para atingir os objetivos propostos, foram entrevistados doze docentes, cada qual pertencente a uma Instituição de Ensino Particular da Grande São Paulo, por meio de entrevistas individuais, semidiretivas, mediante um 
instrumento de coleta de dados, que continha o reconhecimento dos dados pessoais do docente entrevistado e as três questões norteadoras:

O que você entende por competência docente? Em sua opinião, quais são as competências do docente em relação ao ensino da disciplina de administração e enfermagem? $\mathrm{Na}$ sua atuação profissional como docente, como você acha que tais competências influenciam no processo ensinoaprendizagem?

As entrevistas foram marcadas previamente com os docentes, em data e local de preferência dos mesmos. Foram gravadas magneticamente, com autorização dos entrevistados e, transcritas literalmente, sem alteração dos conteúdos das falas. Tais entrevistas não tiveram tempo de duração pré-determinado. Foram finalizadas pelos docentes, quando pareciam esgotar o que tinham a dizer; em geral, porém, tiveram duração de trinta a cinqüenta minutos. As entrevistas se iniciaram com o preenchimento dos dados pessoais pelos próprios docentes, no formulário de instrumento de coleta de dados e, a seguir, com respostas às questões norteadoras do estudo.

A análise do conteúdo de tais falas foi desenvolvida através da técnica de análise temática, a qual seguiu as diferentes fases, organizando-se em torno dos três pólos cronológicos: a pré-análise, a exploração do material, o tratamento dos resultados, a inferência e a interpretação.

Os dados foram categorizados com relação às unidades temáticas emergentes, segundo o significado e percepção dos sentimentos relatados.

\section{RESULTADOS E DISCUSSÃO}

Conforme os critérios propostos para a seleção da amostra foram entrevistados doze professores da disciplina de Administração em Enfermagem, referentes a doze Instituições de Ensino Particulares diferentes.

Para que se tenha uma síntese do perfil dos professores participantes deste estudo, algumas características se fazem importantes ressaltar: a maioria deles possui mais de um vínculo de trabalho, geralmente em outras instituições de ensino privadas. $\mathrm{O}$ tempo de formação dos professores nos Cursos de Graduação em Enfermagem foi bastante variado (cinco, dez, quinze, vinte, trinta e até trinta e seis anos), entretanto não há uma relação de proporção equivalente entre o tempo de formação, o tempo de trabalho na graduação e o trabalho docente na disciplina de Administração em Enfermagem, por exemplo: docentes com cinco anos e vinte anos de formados, ambos com tempo de trabalho na docência de três anos especificamente na referida disciplina.

Quanto à experiência profissional dos docentes é bem diversa (atuação na área assistencial-hospitalar, trabalhos na área gerencial e experiências de trabalho com pesquisa); a titulação dos professores se concentra em nível de Mestrado e Doutorado. Há ainda aqueles que estavam finalizando cursos (um docente estava em fase de conclusão de curso de especialização e outro concluindo o curso de PósDoutorado). A participação dos docentes em cursos na área de saúde/enfermagem é predominante, em detrimento dos cursos de capacitação, na área de educação, para o exercício do ensino, ficando estes, em sua maioria, a cargo das disciplinas específicas dos cursos de Pós-Graduação strictu sensu.

Sendo assim, foi possível verificar que a trajetória profissional de cada docente entrevistado é bem diversificada, em decorrência das diferentes áreas de atuação, das escolhas individuais e também dos projetos aos quais estão inseridos.

As unidades temáticas que surgiram da análise dos discursos dos docentes entrevistados deram origem à quatro categorias adiante apresentadas em que, foi possível apreender, a partir dos discursos transcritos, quais foram as representações dos professores sobre competência docente, sobre suas competências em relação ao ensino da disciplina de Administração em Enfermagem, e como tais competências influenciaram no processo ensino-aprendizagem, na atuação profissional cotidiana. Para eles, competência docente se expressa por:

\section{Saber fazer bem: a consciência e a prática profissional}

- Conhecer e transmitir conhecimentos

- Gerenciar o processo ensino-aprendizagem

- A necessidade de integrar conteúdos entre as disciplinas

Nessa unidade temática, os docentes traduzem que competência docente é um saber fazer bem, mas um saber articulado a conhecimentos, habilidades e atitudes, traduzidos, na prática docente, em conhecimentos teóricos, em habilidades de transmitir esses conhecimentos, de envolver o aluno para que ele descubra suas potencialidades e em atitudes que irão facilitar o gerenciamento do processo ensino-aprendizagem, além da questão da interdisciplinaridade que, segundo as falas dos professores, exige mais do que uma mudança de alguma prática pedagógica, uma mudança de comportamento, ou seja, uma atitude interdisciplinar (atitude coletiva). Isto pode ser demonstrado pelos depoimentos a seguir:

Gardênia - Eu acho que competência docente não está relacionada apenas ao conhecimento do conteúdo técnico ou pertinente à disciplina que está sendo ministrada, eu imagino que também seja o conhecimento da teoria tradicional e as habilidades para estar trocando esses conhecimentos com os alunos.

Tulipa - ...ele tem que ter como competência ser claro; tem que conduzir esse grupo de alunos para desenvolver suas próprias capacidades...não dá para trabalhar com a classe inteira como se fosse uma massa homogênea, você vai 
ter que tentar desenvolver a capacidade de cada aluno... e aí que eu acho que a competência do professor de Administração tem que aparecer: ele tem que ser capaz de trabalhar aluno por aluno, sempre a partir de quem é aquele aluno, do que ele busca na Enfermagem e no que a Enfermagem busca nele, tentar fazer as duas coisas se encontrarem em algum momento.

Begônia - Eu vejo que há falta de integração entre as disciplinas - estar trabalhando planejamento em Administração, a colega estar trabalhando planejamento em semiotécnica, semiologia, e o aluno não está reconhecendo que a matriz é a mesma... fico pensando que tipo de arsenal pedagógico se poderia usar para tornar a disciplina de Administração algo mais vivo, integrado e valorizado pelo aluno, porque ele vai dar valor lá no fim da linha...

Este saber fazer bem, como sinônimo de competência, se dá em uma das dimensões da competência que, que pode ser denominada dimensão técnica ${ }^{(5)}$. A autora afirma que o saber e o saber fazer se traduzem em domínios de conteúdos de que o professor necessita para desempenhar o seu papel, isto é, aquilo que se requer dele socialmente, articulado com o domínio dos conteúdos e das estratégias que permitam a ele realizar bem seu trabalho. Aqui, percebe-se uma tendência dos professores em privilegiar a dimensão técnica do ensino-aprendizagem, no que diz respeito à capacidade de lidar com conteúdos e à habilidade de construí-los e reconstruí-los com os alunos, em detrimento das outras dimensões, também discutidas pela mesma autora: dimensão política, ética e estética.

\section{A capacitação do professor como desafio profissional}

\section{- A necessidade de atualização de conhecimentos específicos da área relacionados aos aspectos legais do ensino} - As especificidades para atuar no ensino da administração

Nesta segunda categoria, os discursos da maioria dos professores revelam que competência docente também está centrada no âmbito da sua capacitação, capacitação essa que o professor deverá buscar através de treinamentos, estudos continuados, cursos de aperfeiçoamento e aprimoramento, fazendo com que ele se mantenha sempre atualizado em seus conhecimentos para acompanhar as mudanças. Aqui, nota-se que a questão da atualização do conhecimento, da possibilidade e da disponibilidade de aprender sempre, acompanhando as tendências atuais do mundo do trabalho e dos conteúdos ministrados na disciplina é significativa para o entendimento da competência docente. Neste sentido, também o docente deve estar preparado e capacitado para dominar temáticas específicas que se incluem no cerne da disciplina e que se constituem em ferramentas ou instrumentos da gerência de enfermagem, tais como: liderança, comunicação, tomada de decisão, relacionamento interpessoal e trabalho em equipe. É possível conferir tais questões pelas falas a seguir:
Acácia - Primeiro ele precisa ter conhecimento das questões globais, sociais e políticas que também são importantes... ele precisa estar totalmente atualizado do que está acontecendo no mundo, se não ele não consegue falar em Administração em Enfermagem...

Gérbera - O docente, para ser competente, tem que conhecer uma boa parcela de gerenciamento, liderança. Assim, ele vai poder transmitir teoricamente e também preparar os alunos em Administração para o gerenciamento, para a liderança, trabalho em equipe... o docente tem que ser competente em comunicação para transmitir a necessidade dessa competência que o futuro aluno enfermeiro terá que ter como sua arma de trabalho.

Na capacitação do professor há uma lacuna existente relativa à área da prática de enfermagem, que poderia ser amenizada pela integração docente assistencial que vem sendo reconhecida, como de grande valia, para a formação discente $^{(2)}$. Nessa perspectiva, o conceito de integração docente assistencial $^{(6)}$, pode ser concebido como a união de esforços em um processo de crescente articulação entre instituições de educação e de serviço de saúde adequados às reais necessidades da população, à produção de conhecimentos e à formação de recursos humanos necessários.

\section{A expressão profissional do professor diante do aluno}

Nesta categoria, aparecem os aspectos da referência e do modelo profissional como definição de competência docente. Tal referência de profissional está ligada a questões éticas, a questões de valores, em que a competência se demonstra através do compromisso, da coerência entre discurso e prática e, também, da sustentabilidade do que se acredita e do que se é. Os discursos se encaminham no sentido de que a aprendizagem se faz por observação de modelos de papel profissional. Nota-se, na fala ilustrativa desta categoria, a presença da dimensão não só técnica, mas ética e política da competência docente:

\begin{abstract}
Dália - Não adianta você estar falando uma coisa que você não passa a imagem de... isso influencia bastante... até eu vejo assim... os alunos perguntam: professora, onde você trabalha você consegue fazer isso? Às vezes vão até conhecer o local e vêem que isto é possível; o que você está passando é possível, está sendo realmente utilizado na prática... então a atuação, a forma como o professor atua na sua vida profissional e como ele passa para o aluno influencia bastante... então a forma pela qual o professor atua dentro da sala de aula será extremamente fundamental para que o aluno tenha um espelho, um guia de como ele vai atuar na vida profissional e de como ele vai resolver esses medos dele...
\end{abstract}

Nada é mais desesperador quando um professor diz: Olhe, é fácil, faça como eu!, embora ninguém tenha entendido como ele age e todos se sintam incapazes de imitá-lo. Um professor não deve esperar que os alunos percorram, em alguns dias, o caminho que ele percorreu em $10 \operatorname{anos}^{(7)}$.

$\begin{array}{rr}\text { Rev Esc Enferm USP } & \text { O significado de competência para } \\ 2006 ; 40(3): 336-42 . & \text { odocente de administração em enfermagem } \\ \text { www.ee.usp.br/reeusp/ } & \text { Nimtz MA, Ciampone MHT. }\end{array}$


Os professores devem compreender o tempo de cada aluno e, assim, serão verdadeiramente referências se buscarem o entendimento e trabalharem juntos, reinventando coletivamente a formação, tendo por base os limites de suas práticas pessoais, ao invés de almejarem um modelo elaborado a ser seguido.

\section{A sensibilidade como competência}

Nesta quarta categoria, apenas um professor considera a competência docente estar associada à sensibilidade que ele deve desenvolver para que perceba e ouça os anseios, os desejos e a necessidade de aprendizado dos alunos. Para tanto, o discurso mostra que a disciplina de Administração ocupa um lugar de destaque neste aspecto: por ser algo impalpável, os alunos desenvolvem a habilidade de percepção, o que leva o professor à, cada vez mais, perceber o aluno como pessoa, reconhecendo suas potencialidades, como comprova a fala:

\begin{abstract}
Begônia - Essa habilidade de perceber, que eu acho uma das habilidades principais para ser docente, principalmente para ser docente de Administração, porque colocando a questão do ensino teórico, da formulação abstrata, essa competência de perceber influencia muito nessa disciplina em que você trabalha com a dimensão do impalpável, que é a produção em administrar - ela não é fisicamente visível, e aí perceber se torna algo muito valioso no ensino da Administração; perceber esse aluno - o que ele traz, como ele está vivenciando isso, quais as dificuldades que ele tem, quais as potencialidades, você vai aprendendo que o aluno tem potencialidades, você não pode querer colocalo numa forma, você tem que dar para ele algo que the permita desenvolver suas potencialidades...
\end{abstract}

Perceber o aluno, o contexto em que vive, suas potencialidades, estabelecendo um relacionamento interpessoal baseado em autenticidade, apreço, compreensão empática, confiança e liberdade de ação, auto-avaliação entre outros aspectos é, indiscutivelmente, uma competência sensível que o professor consciente e comprometido deverá desenvolver em prol de formar profissionais preparados às mudanças e transformações que se apresentam.

Para isto, os professores devem se tornar, também, sensíveis aos processos de mudança. Devem ser capazes de conservar e transmitir o conhecimento e os valores essenciais de outrora, assim como o de acolher avidamente as inovações que se fazem necessárias à preparação de um futuro incerto.

$\mathrm{Na}$ abordagem humanista ${ }^{(8)}$, o eixo principal é o sentimento, o aspecto psicológico do aluno. A educação é vista como terapêutica, tornando-se, pois, secundária a transmissão de conteúdos.

\section{CONSIDERAÇÕES FINAIS}

Este estudo chega ao fim com questões extremamente interessantes e instigantes; porém temos como certo a importância de seguir pensando, refletindo acerca da nossa atuação, enquanto docentes da disciplina de Administração em Enfermagem.

Os professores entrevistados, através de seus discursos, demonstraram preocupações, mas, sobretudo, compromisso com seu fazer docente, no sentido de atribuir significado à sua competência expressa na ação pedagógica, que não só se resume apenas em capacidade técnica, mas em atitudes ética, política e humana.

Os dados coletados nesta pesquisa evidenciaram que muitas responsabilidades e atitudes que recaem sobre o professor da disciplina em questão, que independentemente do local onde desenvolve seu trabalho pedagógico, são fontes através da qual cabe pensar uma nova organização deste processo de trabalho que tenha como diretriz o desenvolvimento de competências, habilidades e atitudes nos alunos. $\mathrm{O}$ ensino pautado em competência deve superar o saber fazer e o aprender a conhecer e, necessariamente, deve abarcar as dimensões que têm sido esquecidas - aprender a ser e aprender a conviver. Tais pilares da educação, têm sido discutidos na perspectiva de buscar respostas aos desafios que esta nova visão impõe ${ }^{(9)}$. Embora os professores reconheçam a importância dessas dimensões estarem presentes na sua ação pedagógica, nem todas costumam ser enfatizadas nos planos de ensino da disciplina.

Esta nova organização da ação pedagógica deve estar embasada, portanto, na própria capacitação do docente enquanto professor, que necessariamente perpassa a instância do conhecimento, da especialidade, avançando na direção da interdisciplinaridade, isto é, para além das especificidades de atuação no ensino da Administração.

Para tanto, é essencial que as Escolas de Enfermagem definam suas políticas de desenvolvimento de recursos humanos e propostas compatíveis de intervenção no que diz respeito à capacitação docente para o ensino de Administração em Enfermagem, considerando as dimensões das competências, as atitudes, os valores, a predisposição e os aspectos relativos à filosofia e estrutura organizacional do ensino.

Assim sendo, o processo de capacitação docente, como parte de uma política de desenvolvimento de recursos humanos, deve favorecer a construção de um pensar compartilhado sobre as próprias incertezas e dificuldades do professor, uma autocrítica extremamente salutar, bem como a reconstrução da teoria e prática vigentes, permitindo, ainda, esvaziar os aspectos e ações imediatistas, levando à construção de uma teoria emancipatória, tornando os professores mais sujeitos de sua própria história profissional, fomen- 
tando a concepção e a implementação de novas alternativas diante do desafio a ser hoje enfrentado: o avançar no processo de desenvolvimento profissional, mediante a preparação pedagógica articulada aos processos de desenvolvimento pessoal e institucional que façam evoluir o funcionamento da escola e da aprendizagem de um sistema baseado em repetições para aprendizagem pelo trabalho não dissociado do vivido.

\section{REFERÊNCIAS}

(1) Brasil VV, Alencar CCP, Mucci I. Refletindo sobre a formação e desempenho do docente de enfermagem. Cogitare Enferm. 1996;1(2):81-5.

(2) Peres HHC, Leite MMJ, Kucgant P. A percepção dos docentes universitários a respeito de sua capacitação para o ensino em enfermagem. Rev Esc Enferm USP. 1998;32(1):52-8.

(3) Friedlander MR. A formação do enfermeiro nas próximas décadas. Âmb Hosp. 1995;7(78):57-61.

(4) Minayo MC. O desafio do conhecimento: pesquisa qualitativa em saúde. $7^{\text {a }}$ ed. São Paulo: Hucitec; 2000.

(5) Rios TA. Compreender e ensinar: por uma docência da melhor qualidade. São Paulo: Cortez; 2001.
O exercício do pensar sobre as dimensões da competência como uma prática cotidiana, aprofundando - assim - a construção contínua da identidade do professor de Administração em Enfermagem por meio de processos de profissionalização contínua é, sem dúvida, um caminho a ser trilhado.

(6) Rocha IMB, Sá MPC. Diagnóstico avaliativo da prática da disciplina administração aplicada à enfermagem. Enferm Cient. 1991;1(3):16-9.

(7) Perrenoud P. Dez novas competências para ensinar. Trad. de Patrícia Chittoni Ramos. Porto Alegre: Artes Médicas Sul; 2000.

(8) Almeida MCS. Tendências pedagógicas na formação do enfermeiro na Paraíba [dissertação]. João Pessoa: Centro de Ciências da Saúde da UFPb; 1992.

(9) Antunes C. Como desenvolver as competências em sala de aula. Petrópolis: Vozes; 2001. 